How to capture value from linking to science-driven basic research: boundary crossing inventors and partnerships

Bruno Cassiman, Reinhilde Veugelers and Sam Arts

DEPARTMENT OF MANAGERIAL ECONOMICS, STRATEGY AND INNOVATION (MSI) 


\title{
How to capture value from linking to science-driven basic research: Boundary Crossing Inventors and Partnerships*
}

\author{
Bruno Cassiman \\ IESE Business School, K.U. Leuven and CEPR \\ Reinhilde Veugelers \\ K.U. Leuven, Bruegel and CEPR \\ Sam Arts \\ K.U. Leuven and FWO
}

October 2011

First Version: October 2009

\begin{abstract}
Surprisingly little is known about the actual process of how firms engage in accessing and translating science-driven basic knowledge and turning this into improved applied research productivity. We study this process focused around a research corporation in the microelectronics and semiconductor industry. We show that firms which have a partnership with the research organization where at the same time inventors cross from the research organization into the firm develop higher quality technologies drawing on the basic research knowledge from the research organization. These same firms also spend more effort internally developing these initial technologies into more applied technologies capturing more value from these interactions with science-driven basic knowledge.
\end{abstract}

\footnotetext{
* The authors wish to thank Ajay Agrawal, Dirk Czarnitzki, Lee Fleming, Alfonso Gambardella, Rahul Kapoor, Lori Rosenkopf, Jasjit Singh, Jason Snyder, Giovanni Valentini?, Bruno Van Pottelsberghe, Rosemarie and Arvids Ziedonis and the seminar participants at HBS, Wharton, Michigan, Toronto, UCLA, USC, Bocconi, LMU Munich, HEC Paris, INSEAD, University of Zurich; the MOVE, Alma Graduate School Bologna, ZEW, EARIE, EPIP and REER conferences for useful comments; Andre Clerix, Johan Van Helleputte and IMEC for the collaboration and data. Bruno Cassiman is a research fellow of the SP-SP Research Center at IESE Business School and acknowledges partial financial support from the Spanish Ministry of Science and Innovation through project $\mathrm{n}^{\circ}$ ECO2009-13169, the Catalan Government Grant no 2009-SGR919 and Fundación Ramon Areces. Sam Arts acknowledges financial support of the Science Foundation Flanders (FWO) and OT/07/11, Reinhilde Veugelers from the Belgian Federal Science Policy Office (Interuniversity Attraction Poles P5/26.A). We are grateful to ECOOM (Policy Research Center for R\&D Monitoring) for providing us access to the patent data.
} 


\section{Introduction}

An important and recurrent concern in economics and management has been to understand to what extent basic research influences technological progress and, ultimately, economic growth. More recent evidence suggests that industrial firms are intensifying their links to basic research performed by universities and other research organizations (Cassiman, Veugelers and Van Looy, INNOS\&T). In spite of these growing connections our understanding at the micro-level of the variety and distribution of these links and how they affect industrial innovation remains unclear. Moreover, concern has been mounting about a widening gap between science-driven basic research and problem-driven applied research leading to what in the biomedical sciences has been dubbed "the valley of death" with a lot of investment in biomedical science leading to few additional lives saved (Butler, 2008).

In this paper we carefully examine the links to a research organization performing science-driven basic research and how such links can have an impact on firms' applied research productivity. We contribute to the literature in several ways. First, we move the analysis to a more disaggregate level. Firms that actively link with basic research will have a portfolio of innovative projects. It is important to examine the effect of the links to basic research on the projects exploiting such links and compare them to similar projects of firms without such links. Second, we examine the effect of different links to basic research. Next to the decision of joining a cooperative basic research program, we also look at the importance of boundary crossing inventors, i.e. inventors that move between basic and applied research organizations. Third, we examine different ways through which firms might capture returns from linking to basic research: the value and quality of technologies developed based on basic research and the success of firms in developing these more basic technologies further into more applied technologies. Together the combination of different links and different measures of capturing value from basic research provide us with a first glimpse into the process of the transfer of basic research into applied technology development.

The links to basic research that we examine are the links through IMEC, a world class research organization performing basic research in micro-electronics and semiconductors. IMEC has the expressed objective to bridge the gap between fundamental research done at universities and applied R\&D in the industry. By financially contributing, firms can become an IMEC partner, i.e. buy "a seat at the table". As a result, they gain access to IMEC developed proprietary basic technologies. In addition, IMEC runs an industrial affiliates program where partner firms can sign up to specific research programs in their area of interest. By sending researchers to participate in the basic research program at IMEC where they interact with researchers of IMEC and other partners involved in the program, partners can 
acquire "a spot in the lab". ${ }^{1}$ IMEC negotiates an elaborate IP agreement with its partners. This allows us to track through patent information the effects of affiliation to IMEC as well as the actual mobility of people and ideas.

The analysis involves comparing patents with different treatments of links to basic research developed at the research organization. Patents of firms that are IMEC partners are compared to patents of non-partnering firms. This allows us to trace the effect of organizational affiliation to the research center. In addition, we compare patents of boundary crossing inventors that have been participating in basic research programs at the research organization versus patents of inventors who did not participate in such a program. This allows us to trace the effect of cross-institutional mobility of researchers. We do this for both partnering and non-partnering firms to examine any differential effect from using an inventor link between partners and non-partners, as the latter can also poach inventors who have visited IMEC to obtain access to the basic research knowledge. This allows us to trace any complementarity effect from combining both types of links.

We find that firms linked to basic research through an IMEC partnership and who use boundary crossing inventors are more likely to develop higher quality innovations. Partner firms continue to build internally on these technologies, improving appropriation of returns from follow-up innovations. Interestingly, inventor mobility is an important link, but only when used in combination with affiliation to IMEC. Poaching of IMEC inventors by firms without an organizational link to IMEC is a less successful strategy. This complementarity between having a partnership and using boundary crossing inventors is particularly important for further developing applied technologies based on this basic knowledge.

While our findings are derived from the analysis of the interaction with a particular research organization in microelectronics and semiconductors, we believe that our findings have more general appeal. First, we argue that the effects of basic research on outcomes need to be analyzed on a subset of technologies of the firms, through a series links and on a selection of outcomes. Otherwise, it will be difficult to pin-point any tangible effects of these interactions with science-driven basic knowledge. Second, connecting to science-based basic research will typically require the crossing of boundaries of research communities and institutions. Tracing these benefits will involve setting up partnerships and organizing interactions at the researcher level. The advantage of strong coordination in the microelectronics and semiconductors in particular fields eases the empirical design for examining these effects. The coordination between different players in the industry (equipment suppliers, semiconductor firms, application developers) might be less of an issue in for example the pharmaceutical industry, but some form of communication between

\footnotetext{
${ }^{1}$ We thank Rosemary Ziedonis for suggesting this use of language.
} 
different research communities will be necessary in order to capture value from sciencedriven basic knowledge.

In the following section we discuss the gaps in the literature and develop some empirical predictions related to the process of how firms effectively appropriate returns for their innovation process through linking to science-driven basic research. Section 3 discusses the empirical setting of IMEC. Section 4 elaborates on our data development and methods while Section 5 presents our results. Section 6 concludes with some caveats and directions for further research.

\section{Bridging the Gap}

Criteria for judging a new scientific contribution differ from the criteria for evaluating a new technological development. For this reason science-driven basic research and applied research are typically developed in distinct institutional settings, which complicates the development of basic research inside firms (Gittelman and Kogut, 2003). Aghion et al (2009) show that universities have more incentive to engage in early stage science-driven basic research. Closer to commercialization firms are willing to step in and take over the projects as they have an incentive to direct this research towards completion. Lacetera (2009) argues that by outsourcing R\&D projects to universities, firms provide a credible commitment not to abort or alter projects with a more basic character and less certain commercial outcomes. These projects are of intrinsic value to university researchers responsive to the incentives defined by their community of peers. As a result, a gap between applied technology development at firms and more basic research in other organizations needs to be bridged before basic research can be translated and developed into new applied technologies.

Bridging these institutional barriers? is not trivial. This is particularly the case as tacit knowledge plays an important role in the basic research environment. Bessen (2011) argues that the tacitness of knowledge is endogenous. Organizations will only cover the cost of codifying knowledge whenever the benefit is sufficiently high. Hence, we should expect basic research knowledge to be less codified as it is harder to appropriate returns to this knowledge.

As a consequence of the existence of this organizational gap between science-driven basic research and problem-driven applied research and the tacitness of the knowledge involved, crossing organizational boundaries seems an important requirement for firms to access basic research knowledge with an important scientific content. Non-codified knowledge impedes the use of contracts as mechanism to transfer non-codified knowledge between organizations. Other transfer mechanisms of the embodied kind are more appropriate, involving inventors with a scientific profile as bridge between these two environments. Zucker \& Darby (2001) for instance, find star-scientists in bio- and nano-technology to travel 
with their knowledge in order to assure the correct translation and development of the basic research knowledge into new products and processesPublic policies around the globe promote active collaboration and personnel exchange between universities and industry, such as the NSF Grant Opportunities for Academic Liaison with Industry program in the US (Dietz and Bozeman, 2005). However, little empirical work has explicitly examined who these boundary crossing researchers are and how they can effectively bridge scientific and technology communities (Allen, 1977, Tushman \& Scanlon 1981, Dietz and Bozeman, 2005, Breschi and Catalini, 2010).

\subsection{How to bridge the Gap?}

The literature has highlighted two modes to transfer knowledge across organizational boundaries: firm level connections and "mobility" of individual researchers.

At the firm-level, the most widely studied mechanism is partnerships between firms and universities or other multidisciplinary research organizations. The pre-eminence of cooperative agreements as a mechanism to access basic research is reminiscent of the importance of crossing institutional boundaries for effective knowledge transfers (Kogut and Zander, 1992; Rosenkopf and Nerkar, 2001). This holds in particular for more tacit sciencebased technologies (Gittleman and Kogut, 2003; Bessen, 2011). To study the effect of such cooperative agreements on firm performance, the largest set of empirical papers uses a (knowledge) production function approach (e.g. Audretsch and Stephan, 1996; Zucker et al 1998; Cockburn and Henderson, 1998; Brandstetter and Sakakibara, 1998). The empirical evidence from these studies find a positive effect from cooperation with universities and public research organizations on innovation productivity and innovative sales, at least for firms with own R\&D capacity (Belderbos et al, 2004; Belderbos et al, 2006). This latter result supports the complementarity between cooperation with these research organizations and internal R\&D. Beyond partnerships with research institutes, also ties with academic star scientists, either through co-publications or board positions, are, especially in biotech, found to lead to more patenting (Henderson and Cockburn, 1996; Zucker et al, 2002; Cockburn and Henderson, 1998); more "important" patents: i.e. international patents (Henderson and Cockburn, 1994); and a higher average of quality adjusted patenting (Zucker and Darby, 2001; Zucker et al, 2002).

At the inventor level, those inventors co-publishing with universities are found to generate patents that exploit more prominently (citations to) science, confirming their boundary spanning role. These inventors also produce patents with shorter lags between existing inventions and new firm inventions in the pharmaceutical industry (Fabrizio, 2009). The involvement of an academic inventor in the invention team is found to lead to more valuable patents (Czarnitzki et al., 2011). More mobile researchers are found to have better 
access to resources and networks (Cañibano, Otamendi and Andujar, 2008) and consequently have a higher innovative performance (Hoisl, 2007; Palomeras, 2010). Improved innovation performance is also found for the firms hosting mobile researchers (Song, Almeida and $\mathrm{Wu}$, 2003; Rosenkopf and Almeida, 2003; Singh, 2008), and even for the firms losing their inventors (Corredoira and Rosenkopf, 2010; Oettl and Agrawal, 2008). As a result, mobility across firm boundaries relates to more effective transfer of knowledge (Singh and Agrawal, 2011).

While the existing firm level empirical analyses typically find a positive relation between science-driven basic research activities of the firm and innovation outcomes, these analyses pay little attention to the actual micro-level mechanisms that link science-driven basic research activity to innovation performance. At the same time the invention and inventor level analyses do not control for organization level connections of the firms. They limit themselves to inventor networks without superimposing the different organizational structures in which these inventions are embedded, that will affect the incentives of these inventors to develop, communicate and appropriate returns to these science-driven basic research activities (Breschi and Catalini, 2010).

Based on the literature, we argue that the spanning of organizational boundaries should be more effective to access science-driven basic knowledge advances and translate this into these technological advances. Through the crossing of organizational boundaries by inventors within the right organizational setting the frictions in this knowledge transfer process can be minimized. Especially, because of the tacitness and complexity of know-how underlying leading edge research, researcher involvement and mobility should play a pivotal role within any cooperative agreement across different institutions. We will distinguish between these pure boundary crossing inventor links relative to more structured organization level partner links. More importantly, we will examine the interaction between firm and inventor level boundary spanning mechanisms, looking for any possible complementarity between both types of links at the invention level. While both partner and inventor links might be considered important to access science-driven basic research, the complementarity between them might be fundamental in capturing returns to tapping into basic research. Organizational level commitments provide the right incentives for researchers actively moving in and out of basic research to transfer their knowledge and develop it into applied technologies.

Our paper most closely relates to the study of Ziedonis and Ziedonis (2005) on how Sematech, a research consortium specialized in semiconductor manufacturing, mediates as performer and broker of R\&D for its member firms. The authors find that technologies developed by the consortium or one of its partners are more valuable, particularly for its members who build on these patents more extensively and more rapidly compared to non- 
members. This is particularly the case for patents developed by the consortium itself. Given the particular features of our research setting we are able to better identify technologies that are extracted from IMEC by partner firms and delve deeper into the boundary crossing inventor links and their effects on these technologies as we discuss in more detail below.

\subsection{How to benefit from bridging the Gap?}

Any explanation for why firms tap into science-driven basic research knowledge needs to argue that ultimately basic research enhances firms' performance (Nelson; 1959; Evenson and Kislev, 1976; Cassiman, Perez-Castrillo and Veugelers, 2002). Unfortunately, we still understand little about the actual process of how firms incorporate and benefit from basic research knowledge.

Basic research can enhance innovative performance by increasing the average quality of the technologies produced. Basic research serves as a map for technological landscapes guiding applied research in the direction of most promising technological venues avoiding thereby wasteful experimentation (Fleming and Sorenson, 2004). A better and more fundamental understanding of the technology landscape encourages non-local search for improving technologies as opposed to local search, leading to more diverse research projects being explored with higher potential pay-offs.

Firms will need to develop the technologies based on science-driven basic research into more applied technologies ready for commercialization. Probably the most discussed argument of how actively engaging in basic research might increase applied research productivity is the fact that basic knowledge leads to a better identification, absorption and integration of external (public) knowledge (Cohen and Levinthal, 1989; Gambardella, 1995; Cassiman and Veugelers, 2006). Faster identification, absorption and integration of external knowledge in turn leads to increased productivity of the applied research process, resulting into new technologies (Fabrizio, 2009; Cassiman et al., 2008). This process of integration requires firms to develop the initially acquired technologies even further into applied technologies and eventually into commercializable products and processes leaving a trace of technologies linking the basic research knowledge to actual applied technologies of the firms. In addition, more basic knowledge can simultaneously fertilize different research projects (Cockburn and Henderson, 1998), again requiring the firm to develop generic insights gleaned from basic research into more applied technologies and spurring additional technology development within the firm.

In summary, science-driven basic research should stimulate the quality of the applied technologies developed by firms. In addition, we would expect firms to take advantage of basic research by building on these knowledge flows through the internal development of commercially viable technologies and products. The process through which firms benefit from science-driven basic research requires firms to set up mechanisms to bridge the 
community and institutional gaps discussed before in order to access and develop higher quality technologies. These technologies subsequently need to be developed further internally for the firm to appropriate returns to more applied, but related technologies.

In this paper, we will attempt to lay bare this process of how firms can capture value from linking to science-driven basic research and transfer the linked basic research into applied technology development. By considering together the combination of different links and different measures of capturing value from basic research, we provide a first glimpse into this process. We do this for the case of a particular research organization in the microelectronics and semiconductor field.

\section{Research Setting: microelectronics and IMEC}

In our analysis we focus on the micro-electronics industry and analyze the effect of links with IMEC - the Interuniversity Microelectronics Center - a world class research institute with a mission to be a bridge between science-driven basic research at universities and problemdriven applied research in industry.

\subsection{Links to basic research in the micro-electronics industry}

The micro-electronics industry is an interesting environment for testing effects of links with science-driven basic research. First, academic research is often at the forefront of breakthroughs in nano-electronics, and for this reason companies are seeking to cooperate with universities and research institutes to tap into emerging research opportunities as early as possible. Academics are at the forefront of discoveries within their field, but the challenge remains to bridge the large gap between the application-oriented needs of the industry and the results from scientific research performed at universities and research institutes.

Second, in the semiconductor business technological knowledge is mostly tacit in nature. Knowledge sharing via researcher interaction and mobility between firms and research organizations is shown to be the crucial mechanism to bridge this gap (Meyer-Krahmer and Schmoch, 1998). In addition, patenting is a standard practice in this industry (Hall and Ziedonis, 2001) and as a result, patents provide a clear window on the technology and innovation activity in the industry.

\subsection{IMEC as link to science-driven basic research}

IMEC was founded in 1982 by the regional Flemish government in Belgium as a non-profit organization with a mission to bridge the gap between fundamental research at universities and $R \& D$ in the industry. The center was built on the academic reputation and prominence of the electrical engineering department of the University of Leuven. The center's involvement 
in the scientific community is illustrated by its close collaboration with world-class universities, by the numerous conference participations and publications from its researchers and by the presence of pre-doctoral researchers at its laboratories. ${ }^{2}$

At the same time, IMEC is closely connected to industry. The board of directors includes delegates from industry who stipulate the center's strategic roadmap focused on precompetitive application-oriented technologies three to ten years ahead of industrial needs. IMEC was able to attract top industry leaders such as Intel, Samsung, Texas Instruments, Micron, NXP, Hynix, Elpida, Infineon, Panasonic, TSMC, Sony, Qualcomm and ST Microelectronics willing to pay the hefty fees to become a partner. With IBM in Albany, IMEC in Leuven has become one of the two most important centers for nano-electronic research with an important focus on process technologies.

\subsection{IMEC's Industrial Affiliation Program}

IMEC has developed a unique business model which stimulates the interactions of scientific and industrial researchers in order to facilitate cross-fertilization of ideas. In IMEC's Industrial Affiliation Program participating companies share costs, risks, human resources and intellectual property while engaging in collaborative $R \& D$ on more generic technologies. Each partner firm can send researchers to collaborate in the programs in which the firm participates. Guest researchers, including academic and industrial researchers affiliated to one of its partners, conduct research at the IMEC laboratories in close collaboration with other researchers. Around 15 different industrial affiliation programs were running in 2010, of which a large majority in the Process Technology Unit, focused at the next generation of semiconductors. Besides IMEC's own research personnel (about 1000), more than 520 guest researchers with 60 different nationalities were conducting research at IMEC's laboratories in 2010, including 344 industrial researchers.

\subsection{IMEC's IPR-model}

Crucial for its industrial affiliation program business model is an aligned Intellectual Property (IP)-strategy so that all collaborating partners are able to build their own and unique IPportfolio on top of shared IP. IMEC has elaborated an IP-strategy to stimulate this technology development and to limit blocking amongst its corporate partners (Van Helleputte, 2004). ${ }^{3}$ The basic platform technologies are accessible to all its partners. These technologies, developed by IMEC or by IMEC in collaboration with partners, are still in a precompetitive

2 In 2010, IMEC was collaborating with approximately 200 universities worldwide in its core CMOS (Complementary Metal Oxide Semiconductor) division only and hosted 194 visiting PhD students at its research facilities. IMEC's own researchers, around 1000, published more than 1,750 scientific articles in 2009.

${ }^{3}$ Johan Van Helleputte is the director for strategic development at IMEC. 
phase and require additional $R \& D$ to be ready for final application. Corporate partners can build on these technologies to develop proprietary IP in line with their own commercial needs. All technology developed at the IMEC laboratories, in execution of dedicated programs by academic or industrial researchers, is contractually co-owned by IMEC unless otherwise contractually stated. Partners gain access to these technologies, as far as needed for the exploitation of the program, via a non-exclusive and non-transferable license. Technologies which result from proprietary research activities within IMEC or at the company are assigned exclusively to the partner. These technologies should represent an important part of the return on the firm's investment in IMEC.

IMEC's business model and the corresponding IP-model are recognized worldwide as a successful medium to stimulate industry-science links, R\&D collaboration and ultimately technology development in the industry. For our analysis, it allows to track the mobility of people and ideas around IMEC, as will be detailed in the next section.

\section{Data and Methodology}

\subsection{Data and Sample}

Our dataset is constructed by exploiting IMEC's basic IP-model. First, we collected all patent applications filed by IMEC between 1990 and 2005 which we retrieved from the Worldwide Patent Statistical Database (PatStat edition April 2008). This set of patents was validated by IMEC. ${ }^{4}$ From this sample of 578 IMEC patents, we identified 531 unique inventors - IMEC inventors $^{5}$ and we retrieved all subsequent patents in the patent database where these IMEC inventors are listed as an inventor. ${ }^{6}$ From this sample of subsequent patents we then identified all patents from IMEC inventors where the inventor was not on the IMEC payroll at the time of application for this subsequent patent and where a private company is the owner of the patent. We name the IMEC inventors listed on these patents boundary crossing inventors as they have been active as an IMEC inventor in the generation of IP at IMEC at some point in their career and are not an IMEC employee at the time of patenting this subsequent company patent which implies some mobility event crossing organizational boundaries during the

\footnotetext{
${ }^{4}$ These patents include 281 EPO, 255 USPTO and 42 PCT patent applications

${ }^{5}$ Note that given the structure of the IMEC programs these IMEC inventors are not necessarily formal IMEC employees as IMEC hosts many different types of researchers, including IMEC employees, affiliate partner employees, post-docs, doctoral students and master students, academic faculty, etc... Inventors listed on patents have contributed to the invention, but do not necessarily have any legal right to the invention.

${ }^{6}$ All different name variants and corresponding person identification numbers of this set of inventors were retrieved using search keys to take into account different spellings. The match of inventor names was made based on matches of name, first name, initial and address. In the case of differences in addresses or names, we checked the technology field of the patent and the applicant name to determine a match. While this rigorous approach might lead to false negative matches (type I error), it minimizes/eliminates false positive matches (type II error). Given our objective to trace inventor interaction and mobility, this conservative approach seems more appropriate.
} 
IMEC inventor's career. ${ }^{7}$ Finally, we also collected all subsequent patents citing the set of 578 original patents owned by IMEC. These citing patents are posterior to the development of this IMEC technology but share the same technological space as the IMEC patents and, therefore, provide a reasonable comparison group for our selection of patents with a boundary crossing inventor from IMEC. ${ }^{8}$

Our final sample of company patents used consists of 1,089 USPTO patents - 221 patents with a boundary crossing inventor and 868 citing patents - from 87 companies, of which 33 are IMEC partners, with 1,835 unique inventors of which 62 are boundary crossing inventors. ${ }^{9}$

Based on our sample construction we define four types of patents along two key dimensions:

Imec Inventor Patent If $_{(}(\in\{0,1\})$ indicates that patent $i$ of firm $f$ has a boundary crossing inventor and Imec Partner Patent ${ }_{i f}(\in\{0,1\})$ indicates that patent $i$ belongs to an IMEC partner firm, i.e. firm $f$ is an IMEC partner. ${ }^{10}$

The four patent types are:

- Boundary-Crossing-Partner patents are patents assigned to an IMEC partner organization (i.e. a member of its industrial affiliation program) and developed by a boundary crossing inventor, i.e. an inventor that has been active in the generation of IP at IMEC at some point earlier in his career but currently not an IMEC employee:

$$
R_{i f}^{B C P}=\text { Imec Inventor }_{i f} \times \text { Partner }_{i f}
$$

\footnotetext{
${ }^{7}$ IMEC has a database with all researchers which have been working at IMEC for at least one month (own personnel as well as visitors) and their status. The use of detailed personnel data obtained from IMEC for all IMEC inventors in our sample allows us to identify the affiliation of an inventor at a particular moment in time. Not all inventors in our sample were found in the database. For those which were potential boundary crossing inventors, we conducted a web search to find additional information on their employment. Inventors which were working for the assignee company at the time of patenting are treated as boundary crossing inventors while those for which we don't find information on their affiliation or who weren't working for the assignee company were excluded from further analysis. ${ }^{8}$ Note that the patents with a boundary crossing inventor do not necessarily cite any of the IMEC patents. But they have an inventor in common with at least one of these patents. In the robustness checks we will look at alternative comparison samples.

${ }^{9}$ The initial sample consists of 5,802 patents (825 IMEC patents, 1,038 patents from IMEC inventors and 3,939 other patents citing IMEC patents), 7,566 unique inventors and 1,348 unique applicants, including around 1,200 companies, 82 universities and 66 research centers. For the remainder of the analysis, we restrict attention to USPTO patents only $(3,606)$ and subsequently eliminate patents (co)assigned to IMEC (302), patents not assigned to companies (488), patents from companies with less than 4 patents in our sample (502), patents which do not share the same technological space as the IMEC patents (65), patents assigned to boundary crossing inventors before they were at IMEC (288), for which we don't have all relevant characteristics (e.g. assignee information (546) or on the affiliation of the IMEC visiting researcher) (326).

${ }^{10}$ In the robustness section we will deal with some obvious selection issues related to both partners and inventors.
} 
- Citing-Partner patents are patents assigned to IMEC partners citing IMEC-owned patents, but without being developed by a boundary crossing inventor:

$$
R_{i f}^{C P}=\left(1-\text { Imec Inventor }_{i f}\right) \times \text { Partner }_{i f}
$$

- Boundary-Crossing-NonPartner patents are patents assigned to non-partner companies, but that have a boundary crossing inventor as an inventor on the patent:

$$
R_{i f}^{B C N P}=\text { Imec Inventor }_{i f} \times\left(1-\text { Partner }_{i f}\right)
$$

- Citing-NonPartner patents are patents assigned to non-partner companies, citing

IMEC patents but without being developed by a boundary crossing inventor.

$$
R_{i f}^{C N P}=\left(1-\text { Imec Inventor }_{i f}\right) \times\left(1-\text { Partner }_{i f}\right)
$$

The classification of the patents according to this methodology allows us to estimate the impact of boundary crossing inventors - a spot in the lab - and/or firm partnerships - a seat at the table - at the invention (patent) level. ${ }^{11}$ The strongest link is a combination of boundary crossing inventors and a partner link, as is the case for Boundary-Crossing-Partner patents. Patents that only have an institutional partner link with the research center are Citing-Partner patents, while Boundary-Crossing-NonPartner patents are patents with only an inventor link to IMEC. These are most likely poaching cases whereby a non-partner company hires away an IMEC inventor. Finally, Citing-NonPartner patents don't have a partner nor inventor link except for the fact that these patents cite IMEC patents and, hence, were developed in the same technology space. These are the ultimate control group for comparison with our various patent types. Note that in contrast to some of the literature, we do not argue that a citation by a firm patent to IMEC technology constitutes a genuine knowledge link. We use citations only for identifying patents that are related in technology space and, hence, provide an even tighter control on the type of technologies considered.

Table 1 below shows the classification of the types of patents according to the links with IMEC and the number of observations for each type.

Insert Table 1 here

\subsection{Empirical Model}

By classifying all patents according to boundary crossing inventor and/or partnership links with IMEC, using the Citing-NonPartner patents as the base case, we can estimate the impact of different links and their interactions. As the earlier discussion suggests, we consider different outcomes as measures of the effects of these inventor and/or partner links with

\footnotetext{
${ }^{11}$ Note that these Citing Patents necessarily are developed after the background technology of IMEC has been developed. Similarly, patents with boundary crossing inventors have been developed after the inventor passed through IMEC.
} 
IMEC. The basic empirical model and the hypotheses tests have a similar structure across the various outcomes considered, as described below.

Let $V_{i f}$ be our dependent variable which measures a key characteristic of patent $i$ of firm $f$.

We estimate a regression of the following form: ${ }^{12}$

$$
V_{i f} \approx \alpha+\beta_{p} P_{i f}+\gamma_{F} F_{f(t)}+\sum_{x \in\{B C P, B C N P, C P, C N P\}} \theta_{x} R_{i f}^{x}+\delta_{k}+\mu_{t}+\epsilon_{i f}
$$

Where

$$
\begin{aligned}
& P_{i f}=\text { Patent level variables } \\
& F_{f(t)}=\text { Firm }- \text { Year variables } \\
& \delta_{k}=\text { Technology Class Fixed Effect } \\
& \mu_{t}=\text { Year Fixed Effect }
\end{aligned}
$$

The $\theta_{x}$ where $x \in\{B C P, B C N P, C P, C N P\}$, are our key parameters of interest in these regressions. Earlier work has found that either partner links or boundary crossing inventor links affect $V_{i f}$. Our more refined empirical predictions on the effects of mechanisms for bridging the gap between science-driven basic research and problem-driven applied research discussed earlier can be translated in the following tests.

\section{Link Test:}

- A Boundary Crossing Inventor link matters; both for partner and non-partner firm patents:

$$
\theta_{B C P}>\theta_{C P}(L T 1.1) ; \theta_{B C N P}>\theta_{C N P}(L T 1.2)
$$

- A Partner link matters both for boundary crossing inventor patents and non-boundary crossing patents:

$$
\theta_{B C P}>\theta_{B C N P}(L T 2.1) ; \theta_{C P}>\theta_{C N P}(L T 2.2)
$$

We did argue that boundary crossing inventors and partner links are complementary:

Complementarity Test: Complementarity exists between Partner and Inventor Links when:

$$
\theta_{B C P}-\theta_{B C N P}>\theta_{C P}-\theta_{C N P}(\mathrm{CT})
$$

\footnotetext{
${ }^{12} \mathrm{By}$ “ $\approx$ " we indicate that we are not necessarily estimating a linear equation as we describe below.
} 


\subsection{Dependent Variables}

In our study of the effects of boundary crossing inventors and partner links we consider two types of effects on the innovation process of the firm: quality of innovations being developed subsequently to the linking activity and the internal translation and further development effort.

\subsubsection{Quality of Innovation}

To evaluate the effect of linking to science-driven basic research through IMEC on the technological impact and the economic value of an organization's patents, we employ a commonly used indicator in past studies to measure patent quality. The most used indicator of patent value and quality is the number of forward citations received from subsequent inventions. The number of forward citations a patent receives is related to its technological importance (Albert et al., 1991; Carpenter et al, 1993; Henderson et al., 1998; Jaffe et al., 2000), social value (Trajtenberg, 1990), private value (Harhoff et al, 1999; Hall et al., 2005), patent renewal (Harhoff et al, 1999) and patent opposition (Lanjouw and Schankerman, 1999). Research based on an inventor-targeted survey to estimate the economic value of European patents also reveals that although forward citations carry a lot of noise, it proxies closely the estimated economic value (Gambardella et al., 2008). We calculate the total of all forward citations received by an individual patent since the year of application. We also use a fixed citation window of 3 years.

We expect a positive correlation between boundary spanning links and forward citations, i.e. Boundary-Crossing and/or Partner patents are expected to have a higher rate of forward citations as compared to the base case of Citing-NonPartner patents. Furthermore, comparing Boundary-Crossing-Partner patents with Citing-Partner patents would test for the additional effect of a boundary crossing inventor link for partner firms (LT1.1) while comparing Boundary-Crossing-NonPartner patents with Citing-NonPartner patents would test for this effect for non-partners (LT1.2). Comparing Boundary-Crossing-Partner with Boundary-Crossing-NonPartner patents would test for the additional effect of an institutional partner link for firms using a boundary crossing inventor link (LT2.1) while comparing Citing-Partner patents with Citing-NonPartner patents would test for this link for firms using a boundary crossing inventor link (LT2.2).

If inventor and organizational links are fully complementary, i.e. boundary crossing inventor links are more effective for partners and/or partners get more value out of boundary crossing inventors, we have that the marginal effect of a crossing inventor on a partner patent is larger than the marginal effect of such an inventor for non-partners (CT).

To estimate the technological impact of the patents as measured by their number of forward citations, we use count models as the dependent variable is a non-negative integer. The specification of our baseline model as a Poisson or a Negative binomial model follows 
previous studies. We first estimate the Poisson quasi-maximum likelihood model (PQML) because this renders consistent estimates given that the mean is correctly specified (Gouriéroux et al., 1984). We also use a Negative Binomial model which allows for overdispersion and heterogeneity across observations. Moreover, our sample has a large number of observations with zero value ( $31 \%$ of 1,089 patents). To deal with this issue, ZeroInflated Poisson (ZIP) and Negative Binomial models (ZINB) are estimated (Long, 1997).

\subsubsection{Internal Development Effort}

Firms working in a particular technology area can build on their internal knowledge. Selfcitations reflect this capacity of the firm to build further on its existing internal technologies (Hall, Jaffe, \& Trajtenberg, 2001, 2005; Jaffe \& Trajtenberg 2002). We calculate the proportion of forward citations of our sample patents that are self-citations as an indicator for the extent to which linking firms succeed to build forward on these technologies . Hence, the proportion of self-citations reflects the extent to which the company is able to, or attempts to, appropriate the returns to its linking efforts. ${ }^{13}$

We expect firms with links to IMEC to have a higher capacity and incentive to build further on IMEC related internal knowledge. In particular, comparing Boundary-CrossingPartner patents with Boundary-Crossing-NonPartner patents (LT2.1) and Citing-Partner patents and Citing-NonPartner patents (LT2.2) tests for the importance of a partner link with IMEC. Furthermore, comparing Boundary Crossing-Partners with Citing-Partners (LT1.1), tests for the additional effect of an inventor link next to an institutional link. These inventor and organizational links are complementary when boundary crossing inventor links are more effective for partners and/or partners can translate better with boundary crossing inventor links (CT).

To estimate the importance of building further internally on IMEC related technology we regress the proportion of self-citations of the patent on our control variables and patent indicators for the type of link with IMEC, while controlling for the total number of forward citations received. We use OLS,heteroskedastic Tobit and fractional logit models (Papke and Wooldridge, 1996) .

\subsection{Control Variables}

To obtain consistent estimates, we include control variables at the patent level and firm level. At the patent level, we first control for 30 patent technology classes as defined by Fraunhofer (FhG-ISI, Germany) based on concordance with IPC codes (OECD, 1994). As pointed out by

\footnotetext{
${ }^{13}$ See also Alcacer and Zhao (forthcoming) where they argue that the regional dispersion of inventors on self-citations allows firms to appropriate returns from inventions in different regions depending on the competitive environment of the region of the focal invention.
} 
Fabrizio (2009), patents in fast evolving technological classes will cite more recent patents on average so that we need to control for this bias. Also, as illustrated by Hall and Ziedonis (2001), citation lags in computers, communications and electronics are relatively short compared to other technological fields. Moreover, different technological classes are characterized by different citation patterns, both in the amount and the scope of citations to patents and scientific literature. Traditional technological fields typically cite more and are cited less, whereas emerging technological fields are cited more but are average in terms of citations made.

Second, we control for changes in citation patterns over time and for truncation by including application year dummies. In addition, we introduce patent scope as the number of core International Patent Classification (IPC) codes listed on the patent. Patent scope could determine the extent of patent protection and monopoly power and thus the economic value of an invention (Scotchmer, 1991). At the same time, more IPC classes covered by the patent could also affect the likelihood of being cited as the patent covers more technology space. The count of citations to scientific work (NPRS) is included as an additional control as more references to scientific work are associated with a higher number of received citations merely because the act of publication allows the ideas underlying the patent to diffuse more broadly and rapidly (Fleming and Sorenson, 2004) or because of possible higher economic value of these patents (Harhoff et al., 2003). Similarly, we control for the number of backward patent references to control for unobserved factors affecting citation behavior.

We include the number of inventors as an additional control because more inventors might lead to a faster and greater diffusion of the tacit and complex knowledge underlying the patent, resulting in different forward citation patterns. This measure is also used to control for the resources invested in developing the technology.

We include for each patent inventor his experience to control for a potential inventor selection issue. Particular types of technologies might be developed by more competent or experienced researchers. We calculate inventor experience as the number of patents filed at the USPTO by the inventors of the focal patent before the application year. We made use of "the careers and co-authorship networks of U.S. patent-holders" data (Lai, D'Amour and Fleming, 2009) to identify inventor histories.

Next, we introduce for each patent additional measures on the organization of $R \& D$ at the firm level to control for firm specific variation at the time of patent application. ${ }^{14}$ Several arguments have been advanced as to why organization size matters for research productivity. First, larger organizations wield more resources and are able to exploit economies of scale in research (Cassiman et al., 2005). Cassiman, Perez-Castrillo and

\footnotetext{
${ }^{14}$ These firm-level variables vary across different patents of the same company applied for at different moments in time. They are calculated at the company application year level.
} 
Veugelers (2002) find that larger firms have an incentive to proportionally invest more in basic research as it increases the productivity of applied R\&D. Second, larger organizational size allows more specialization. In larger firms, researchers work on more projects but are more specialized in the type of projects they engage in (Kim et al., 2004). Third, larger companies are able to exploit economies of scope. As larger firms are active in different product markets and technology domains, more opportunities for exploiting economies of scope within the firm arise (Cassiman et al., 2005; Henderson and Cockburn, 1996). Scale is calculated as the number of US patents filed by the firm in the 5 years before the application year of the patent and Scope as the number of distinct IPC codes of a company's patents in the 5 years before the application year of the patent. Finally, Age Company is included as the number of years since the company's first patent at the moment of the filing of the focal patent. Sorenson and Stuart (2000) find that on the one hand older firms produce more patents, but on the other hand these same firms produce less valuable patents. Moreover, older firms self-cite more and have older backward citations. ${ }^{15}$

\section{$5 \quad$ Results}

\subsection{Descriptive analysis}

Table 2 presents some descriptive statistics for the total sample, while Table 3 gives an overview of descriptive statistics by patent type. The IMEC-owned patents are more likely to cite the scientific literature (non-patent reference binary), confirming the more science-driven basic nature of these patents. But at the same time our selection of patents from IMEC partners and non-partner firms are significantly more likely to cite scientific literature compared to an average US patent which is about $30 \%$.

\section{Insert TABLE $2 \& 3$ here}

When we look at the partner and non-partner patents, we see that Boundary-CrossingPartner patents, which have both a boundary crossing inventor and an institutional partner link to IMEC, receive the highest number of forward citations. This is particularly clear when we restrict the citation window to 3 years, controlling for the exposure time of patents. Citing-Partner patents with only an institutional partner link to IMEC, but without the boundary crossing inventor link, are as likely as Boundary-Crossing-Partner patents to receive forward citations, but the count of these citations is lower. ${ }^{16}$

\footnotetext{
${ }^{15}$ Note that their interpretation of self-citations does not correspond to our notion of appropriation in science intensive businesses. See also Catani (2005) for a similar interpretation of self citations in optical fiber technology.

${ }^{16}$ Ttest on difference of means Boundary-Crossing-Partner vs Citing-Partner: count forward citations within 3 year: $\mathrm{t}=3.83^{* * * *}$;
} 
Both Boundary-Crossing-Partner and Citing-Partner patents are more likely to be built upon internally as the partner is more likely to continue developing technology in that area. Self-citations to these patents are much higher. ${ }^{17}$

In summary, these first descriptive results already indicate that the tighter the link with IMEC, the more able a company seems to assimilate the knowledge captured by the invention and to use this knowledge to develop subsequent inventions. We argued that because of the tacitness and complexity of know how underlying leading edge research, researcher interaction and mobility does play an essential role. We indeed observe that individual inventors visiting the research center in order to collaborate with other industrial and scientific researchers in joint $R \& D$ projects - i.e. boundary crossing inventors - seem to play a decisive role as link between industry and IMEC, but most importantly when they are associated with firms that have an institutional partnership link with IMEC. These descriptive statistics, although not controlling for other factors, are already supportive for the positive impact of IMEC links for firms' technology development, particularly the combined inventor and partner link. Maybe more surprising given all the literature on inventor networks and mobility is the finding that a boundary crossing inventor when he is operating outside an institutional partner link (Boundary-Crossing-NonPartner patent) does not seem to result in higher quality technologies being captured and developed by the non-partner firm.

\subsection{Quality of Innovation}

Table 4 shows the results of our count model estimations: Poisson (1,2), Negative Binomial (3) and Zero-inflated Negative Binomial (4). Regressions (5) and (6) where we estimate a (Zero-inflated) Poisson Count model and use the forward citations received in a 3 -year window as the dependent variable are probably the most stringent specifications. BoundaryCrossing-Partner patents receive between $46 \%$ and $94 \%$ more citations compared to the control group of Citing-NonPartner patents depending on the model selected. For firms that are not IMEC partners, patents developed with the assistance of boundary crossing inventors, are not more valuable compared to patents developed without the assistance from boundary crossing inventors. Our expectation that boundary crossing inventors are a pivotal mechanism for linking therefore only seems to hold for firms that also have an institutional link. This is confirmed by the significance of the LT2.1 test in regressions (5) and (6), which states that a boundary crossing inventor will have a higher effect for partnering than for nonpartnering firms. These results are supportive for complementarity between partner and boundary crossing inventor links. The formal test for complementarity is only significant at $7 \%$ for the fixed citation window results (regression (5)).

\footnotetext{
${ }^{17}$ Ttest on difference of means Boundary-Crossing-Partner vs Boundary CrossingNonPartners: $t=2.98 * * * ;$ Citing-Partner vs Citing-NonPartners: $t=3.23 * * *$
} 
Insert TABLE 4 here

As expected, the scope of the patent (Count IPC) and the number of scientific publications cited by the patent (NPRs) are positively related with the number of forward citations received, while the age of the company is negatively related. Scale of the firm is positive and Scope of the firm is negative, but these coefficients are not estimated precisely across all regressions.

\subsection{Internal Development Effort}

Building further on technology linked to IMEC technologies is an important way to capitalize and appropriate returns from linking to science-driven basic research. As expected, IMEC partners are more likely to build further on these technologies, as indicated by the higher proportion of self-citations received by both Boundary-Crossing-Partner and CitingPartner patents (See Table 5). This result is in line with Ziedonis and Ziedonis (2005), which find that member firms of the SEMATECH consortium are building upon the results of their collective research to a greater degree than are non-member firms. These patents are expected to have on average a $6 \%$ to $10 \%$ larger proportion of self-citations relative to comparable patents by non-partners. Although we find that partner patents with a boundary crossing inventor link have a larger proportion of self-citations compared to patents of partners without a boundary crossing inventor link, this difference is not statistically significant (LT1.1). There is, hence, no evidence of significantly higher effects from the inventor link for partnering firms with respect to the proportions of self-citations.A patent from a non-partnering firm but with a boundary spanning inventor link actually has a significantly smaller proportion of selfcitations compared to patents from boundary spanning inventors at partner firms (LT2.1). This result seems to suggest that if there is no institutional link with IMEC the hiring company is not able to fully appropriate the return to its investments relative to others building forward on the technologies developed by this researcher. Being able to fully exploit the researcher mobility link seems to require a complementary institutional link.

All these findings are supportive of the complementary role of boundary spanning inventors and institutional partnerships in order to better absorb the complex and tacit technological knowledge underlying micro-electronics research through the internal development of the next generation of technologies. The test for complementarity is indeed statistically significant at the $1 \%$ level for the Tobit regressions that control for censoring of our dependent variable.

\section{Insert TABLE5 here}

The count for forward citations is highly significant and positive as a control. Scope of the firms is negatively related to the proportion of self-citations. Together with the negative effect 
of scope on the number of forward citations received this might indicate a loss of focus for the firms with broader scope. The number of backward patent citations (PRS) is positively related to the proportion of self-citations. Our results are consistent across OLS and Tobit specifications.

\section{$5.4 \quad$ Robustness \& Selection}

\subsubsection{Robustness}

Our measure for the quality of patents is the number of forward citations while our measure of internal development effort is the proportion of these forward citations that are selfcitations. One potential concern is that our quality measure is actually driven by the number of self-citations rather than by the total citations received by the patent. In Table 4, in regressions (7) and (8) we re-estimated our specification for forward citations without selfcitations in a 3-year window and for total self-citations as a Zero-Inflated Poisson estimation (ZIP). As it turns out, our results for the forward citations are sensitive to the zero-inflated specification because of the many "0" observations (44\% compared to $31 \%$ for the overall sample). We do find some interesting differences comparing regressions (7) and (8). Consistent with our findings on the proportion of self-citations in total forward citations both Boundary-Crossing-Partner patents and Citing-Partner patents have a significantly higher number of self-citations compared to Citing-NonPartner patents and Boundary-CrossingNonPartner patents have significantly fewer self-citations. When only taking into account citations coming from other firms (regression (7)), we only find that Boundary-CrossingPartner patents have a significantly higher number of forward citations in this specification. These results allows us to better interpret the results on the proportion of self-cites. For Boundary-Crossing Partner patents, the strong positive effect on self-cites rates results from a combination of positive effects on self-cites and external cites, but where the latter is weaker than the former. For Citing Partner patents the positive effect on self-cite rates is due a positive effect on number of self-cites, while external cites are not significantly affected. For Boundary-Crossing-Non-Partner patents, the negative effect on self-cite rates is from a negative effect on self-cites, while external cites are not significantly affected to be able to compensate. These findings are consistent with our interpretation of the results that a combination of boundary crossing inventors and institutional partnership link is important to develop high quality inventions based on their IMEC relation while firms with an institutional partnership link invest more effort in internally developing IMEC related technologies.

\subsubsection{Sample Selection}

Our results on the positive effect of boundary crossing inventor links and partner links on the quality of inventions and the self-citations might be sensitive to the control sample of patents 
selected. As mentioned, we construct our control sample for the sample of boundary crossing patents based on patents that cite a set of IMEC-owned patents. We argued that this helped to construct a sample of patents in the relevant technology field for IMEC related technologies. Nevertheless, we check the robustness of our findings by selecting a more generic and a more restrictive sample of patents. First, we follow standard procedure to construct a control sample of patents assigned to a non-partner company sharing the same technology class (IPC4) as the focal patents with a boundary crossing inventor. Among the group of matching patents based on technology class, we select for each patent in our sample a control patent with the closest application date. Second, as a more restrictive control group we select a similar control sample of patents with the additional requirement that the patent is assigned to the same company to create a stricter control on the boundary crossing characteristic of the inventor listed on the focal patent. Finally, we restrict our actual sample to patents that only cite IMEC-owned patents, i.e. we also restrict the patents with a boundary crossing inventor to patents that also cite IMEC-owned technology. Table 6 presents the descriptive statistics for the different samples together with our original descriptive results. Our results remain valid, but the small sample size precludes us from obtaining significant results for all samples.

\section{Insert TABLE 6 here}

Interestingly, the control groups based on IPC code, and IPC code and firm find an average 3year citation count $(2.10 ; 2.83)$ and self-citation proportion $(0.14 ; 0.15)$ for partner patents that is comparable to or lower than is the case for our control groups of citing patents with 2.38 for the average of 3-year forward citations and 0.20 for the proportion of self-citations. This reassures us that our control group based on citing patents is more restrictive. When restricting the sample to all patents that cite IMEC-owned technology, our results on boundary crossing inventor patents also holds up with an average 3-year forward citation count of 4.25 compared to 4.42 in the case of a partner patent and 1.44 compared to 1.69 for a non-partner patent. But one should note the low number of observations for the boundary crossing inventor patents that also cite the original IMEC technologies which is somewhat surprising.

\subsubsection{Partner and Inventor Selection}

While the empirical results are supportive for the tangible effects of links with IMEC, particularly for the combination of inventor and organizational spanning mechanisms, we need to address potential selection issues at the level of the partner firm and the inventor.

A first important concern is that the positive effect of the partner link on patent quality and in particular on self-citations might be driven by elements that favor a company being a partner rather than the effect of the partner link per se. In an attempt to more formally 
control for this partner selection issue, we estimated the probability of a particular patent to be from an IMEC partner at a particular moment in time in function of patent characteristics, the company's core technological area ${ }^{18}$ the location of its headquarters (USA/Europe/Japan), whether the firm is in the top 25 of largest semiconductor firms as well as its scale, scope and age as defined before. The selection model (see Appendix) results in a pseudo $\mathrm{R}^{2}$ of 0.45 and we make $82 \%$ correct predictions. ${ }^{19}$ Consequently, we calculate the propensity scores to be a partner patent and use kernel matching to compare different matches of patents to examine the robustness of our findings. Results are presented in Table 7.

\section{Insert TABLE 7 here}

The matched patents basically reveal a similar story as our regressions. Compared to the benchmark case of Citing-NonPartner patents, the superior performance of BoundaryCrossing-Partner patents is confirmed: boundary crossing inventors of partners matter for the quality of the technologies developed as shown for the forward citations. The effect of a partner link, i.e. comparing Citing-Partner patents to Citing-NonPartner patents, shows a significant positive effects on self-cites only, effectively testing LT2.2 for this outcome measure. The results from comparing Boundary-Crossing-Partners to Boundary-CrossingNonPartners, i.e. the additional effect of partnership for inventor links, i.e. testing LT2.1, confirms a significantly higher effect from Boundary-Crossing-Partner patents on average quality as well as on self-citations. These results thus confirm the importance of an institutional link to exploit the advantages of an inventor link, even when more carefully matching a partner patent with a non-partner patent through our matching procedure.

A second important concern beyond the partner selection issue is that there might also be an inventor selection issue in case firms would send their more competent researchers to IMEC resulting in the higher perceived quality of boundary crossing partner patents. From interviews with managers from IMEC we learned that this is not necessarily the case because companies do not want to share their most valuable human resources with other firms including competitors - while at the same time making sure that the participating researchers are able of identifying, absorbing and integrating the relevant knowledge. IMEC does attempt to control such behavior by providing partners with regular evaluations of the boundary crossing researchers in the IMEC teams. We attempt to check the inventor selection issue by matching the prior patents of IMEC-visiting researchers, i.e. prior to these visits, with a group of comparable patents applied for by the same firm within the same year. Results obtained

\footnotetext{
${ }^{18}$ Electrical machinery and apparatus, electrical energy; audio-visual technology; telecommunications; information technology; Semiconductors; optics; analysis, measurement, control technology; chemical engineering

${ }^{19}$ The constant only model would correctly assign $56 \%$ of the patents.
} 
from T-tests indicate that the paired group of patents do not differ significantly, ${ }^{20}$ suggesting that there is no obvious inventor selection issue. ${ }^{21}$

\section{Discussion and Conclusion}

In conclusion, we find strong support for IMEC partners to develop higher quality innovations in the technology domain where IMEC is active. Furthermore, partner firms are more likely to build on these technologies internally, improving appropriation of the returns to R\&D. Overall, we therefore conclude that institutionally linking to IMEC has provided some tangible benefits for IMEC partners.

We have found that the boundary crossing inventor link, i.e. researchers of a partner actively engaged in joint research with IMEC are an important link in this chain as they allow the partner to develop higher quality innovations but in particular as they allow to capitalize on the returns from linking to science-driven basic research through internal development of the next generation of commercial technologies. The technologies developed by the bridging researchers are extensively used internally as a platform for further technology development.

As these effects from boundary crossing inventor links are significantly stronger for IMEC partners, this suggests that companies should have a complementary institutional link to benefit from cross-institutional employee interaction and mobility, in particular for establishing cumulative technology development. Hence, boundary crossing inventor links do not tell the whole story. Firms need to buy a seat at the table before a spot in the lab can have any effect.

The results are highly supportive of the paper's research strategy to differentiate among the linking mechanisms - boundary crossing inventors and partnerships - as well as the impact measures - forward citations and proportion of self-citations - considered. At the same time they also suggest important avenues for further research. First, the analysis should extend the set of linking mechanisms (e.g. co-publications). Secondly, more information on how firms organize internally for effective linking from case studies at partnering and nonpartnering firms would be helpful to further fine tune the search for institutional controls on the effects and the partner selection analysis. Particularly critical company characteristics beyond the scale and scope of R\&D and the age of a company need to be factored into explain appropriation success. Thirdly, in order to better understand what makes the IMEC model so successful, a more in-depth study of IMEC is in order. As IMEC is not characterized by major regime shifts over time which would allow pin-pointing critical

\footnotetext{
${ }^{20}$ We found no statistically significant differences between the number of citations received within three years, the proportion of self-citations, the number of IPC codes, the number of backward patent citations, the number of non-patent references and the number of inventors.

${ }^{21}$ In the case that partners are likely to send less competent researchers, this would actually bias the results against us.
} 
characteristics for success, comparing with other research consortia formula is a more promising avenue to understand what makes IMEC special. Sematech and MCC for instance, are alternatively consortia models in semiconductors which differ sufficiently in terms of IP model, public and private funding, collaboration model as well as in success (Cassiman, 1996; Ziedonis \& Ziedonis (2005)) to make for a fruitful comparison analysis.

\section{References}

Aghion, P., M. Dewatripont, J. Kolev, F. Murray, S. Stern. (2009). Of Mice and Academics, mimeo Harvard.

Albert, M.B., D. Avery, F. Narin, P. McAllister. (1991). Direct Validation of Citation Counts as Indicators of Industrially Important Patents. Research Policy. 20(3) 251-259.

Alcácer, J. and M. Zhao. (forthcoming). Local R\&D Strategies and Multi-location Firms: The Role of Internal Linkages. Management Science.

Allen T. J. (1977). Managing the flow of technology. MIT Press.

Audretsch D.B., P.E Stephan. (1996). Company-Scientist Locational Links: The Case of Biotechnology. American Economic Review. 86(3) 641-652.

Belderbos, R., M. Carree, B. Lokshin. (2004). Cooperative R\&D and Firm Performance. Research Policy. 33(10) 1477-1492.

Belderbos, R., M. Carree, B. Lokshin. (2006). Complementarity in R\&D Cooperation Strategies. Review of Industrial Organization. 28(4) 401-426.

Bessen J. (2011). Communicating technical knowledge. Boston University School of Law working paper No. 10-35.

Bozeman, B., C. Boardman (2004). The NSF Engineering Research Centers and the university-industry research revolution: a brief history featuring an interview with Erich Bloch. Journal of Technology Transfer. 29 365-375.

Brandstetter, L. and M. Sakakibara. (1998). Japanese research consortia: a microeconometric analysis of industrial policy. Journal of Industrial Economics 46: 207-233.

Breschi, S. \& Catalini, C. (2010). Tracing the links between science and technology: An exploratory analysis of scientists' and inventors' networks. Research Policy. 39(1) 14-26.

Butler, D. 2008, Crossing the Valley of Death, Nature, 453, 840-842.

Cañibano, C., J. Otamendi, I. Andujar. (2008). Measuring and Assessing Researcher Mobility From CV Analysis: the Case of the Ramon y Cajal Programme in Spain. Research Evaluation. 17(1) 17-31.

Carpenter, M., F. Narin. (1983). Validation study: patent citations as indicators of science and foreign dependence. World Patent Information. 5(3) 180-185. 
Cassiman, B. (1996). Cooperation in Research and Development. Unpublished Dissertation Northwestern University.

Cassiman, B., D. Perez-Castrillo, R. Veugelers. (2002). Endogenizing Know-how Knows through the Nature of R\&D Investments. International Journal of Industrial Organization. 20(6) 775-799.

Cassiman, B., R. Veugelers (2005). R\&D Cooperation Between Firms and Universities: Some empirical evidence from Belgian manufacturing. International journal of Industrial Organization. 23(5-6) 355-379.

Cassiman, B., R. Veugelers (2006). In Search of Complementarity in the Innovation Strategy: Internal R\&D and External Knowledge Acquisition. Management science. 52(1) 68-82.

Cassiman, B., R. Veugelers, P. Zuniga. (2008). In search of Performance Effects of (in)direct Industry Science Links. Industrial and Corporate Change. 17(4) 611-646.

Cattani G. (2005). Preadaptation, Firm Heterogeneity, and Technological Performance: A Study on the Evolution of Fiber Optics, 1970-1995. Organization Science. 16(6) 563-580.

Cockburn, I.M., R. Henderson. (1998). Absorptive Capacity, Coauthoring Behavior, and the Organization of Research in Drug Discovery. The Journal of Industrial Economics. 46(2) 157-182.

Cockburn, I., R. Henderson. (1998). The Organization of Research in Drug Discovery. Journal of Industrial Economics. 46(2) 157-182.

Cohen, W.M., D.A. Levinthal. (1989). Innovation and learning: the two faces of R\&D. The Economic Journal. 99(397) 569-596.

Corredoira, R., L. Rosenkopf. (2010). Should Auld Acquaintance Be Forgot? The Reverse Transfer of Knowledge through Mobility Ties. Strategic Management journal. 31(2) 159-181.

Czarnitzki, D., K. Hussinger, C. Schneider. (2011). Commercializing Academic research: The Quality of Faculty Patenting. Industrial and Corporate Change. 20(5) 1403-1437.

Dietz, J.S., B. Bozeman.(2005). Academic careers, patents, and productivity: industry experience as scientific and technical human capital. Research Policy. 34 349-367.

Evenson, R.E., Y. Kislev. (1976). A Stochastic Model of Applied Research. The Journal of Political Economy. 84(2) 265-282.

Fabrizio, K. (2009). Absorptive Capacity and the Search for Innovation. Research Policy. 38(2) 255-267.

Fleming, L., O. Sorenson. (2004). Science as a map in technological search. Strategic Management Journal. 25 909-928.

Gambardella, A. (1995). Science and innovation: the US pharmaceutical industry during the 1980s. Cambridge University Press.

Gambardella, A., D. Harhof, B. Verspagen. (2008). The value of European patents. European Management Review. 5 69-84. 
Gittelman, M., B. Kogut. (2003). Does Good Science Lead to Valuable Knowledge?

Biotechnology Firms and the Evolutionary Logic of Citation Patterns. Management Science. (49)4 366-382.

Gourieroux, C., A. Monfort A. Trognon A. (1984). Pseudo Maximum Likelihood Methods: Applications to Poisson Models. Econometrica. 52(3) 701-720.

Hall, B.H., R.M. Ziedonis (2001). The determinants of patenting in the US semiconductor industry, 1980-1994. The Rand Journal of Economics. 32(1) 101-128.

Hall, B. H., A. B. Jaffe, and M. Trajtenberg (2001). The NBER Patent Citation Data File: Lessons, Insights and Methodological Tools. NBER Working Paper 8498.

Hall, B.H., A. Jaffe, M. Trajtenberg. (2005). Market Value and Patent Citations. RAND Journal of Economics. 36(1) 16-38.

Harhoff, D., F. Narin, F. Scherer, K. Vopel. (1999). Citation Frequency and the Value of Patented Inventions. The Review of Economics and Statistics. 81(3) 511-515.

Harhoff, D., F. Scherer, K. Vopel. (2003). Citations, Family Size, Opposition and the Value of Patent Rights - Evidence from Germany. Research Policy. 32(8) 1343-1363.

Henderson, R., I.M. Cockburn. (1996). Scale, Scope, and Spillovers: The Determinants of Research Productivity in Drug Discovery. RAND Journal of Economics. 27(1) 32-59.

Hoisl, K. (2007). Tracing Mobile Inventors- The Causality between Inventor Mobility and Inventor Productivity. Research Policy. 36(5) 619-636.

Jaffe, A., M. Trajtenberg, M.S. Fogarty. (2000). The Meaning of Patent Citations: Report on the NBER/Case-Western Reserve Survey of Patentees. NBER Working Paper No. W7631.

Jaffe, A.B. , M. Trajtenberg(2002). Patents, Citations \& Innovations: A Window on the Knowledge Economy. MIT Press.

Kogut, B., U. Zander. (1992). Knowledge of the Firm, Combinative Capabilities, and the Replication of Technology. Organization Science. 3(2) 383-397.

Kim, J., G. Marschke (2009). Research Scientist Productivity and Firm Size: Evidence from Panel Data on Inventors. Pacific Economic Review. 14(4) 516-531.

Lai, R., A. D'Amour, L. Fleming. (2009). The careers and co-authorship networks of U.S. patent-holders, since 1975. Harvard Business School, Harvard Institute for Quantitative Social Science.

Lacetera N. (2009). Different Missions and Commitment Power in R\&D Organization: Theory and Evidence on Industry-University Relations. Organization Science. 20 (3) 565582.

Lanjouw, J.O., M. Schankerman. (1999). The Quality of Ideas: Measuring Innovation with Multiple Indicators. NBER Working Paper No. W7345.

Long, J.S. (1997). Regression Models for Categorical and Limited Dependent Variables. Sage Publications. 
Meyer-Krahmer, F., U. Smoch. (1998). Science-based technologies: university-industry interactions in four fields. Research Policy. 27(8) 835-851.

Nelson, R. (1959). The Simple Economics of Basic Scientific Research. The Journal of Political Economy. 67(3) 297-306.

OECD (1994). The Measurement of Scientific and Technological Activities: Using Patent Data as Science and Technology Indicators, Patent Manual. OECD/GD(94)114, Paris.

Oettl, A., A. Agrawal. (2008). International Labor Mobility and Knowledge Flow Externalities. Journal of International Business Studies. 39(8) 1242-1260.

Palomeras, N., Melero E. (2010). Learning by Hiring as a Driver of Mobility. Management Science. 56(5) 881-895.

Papke, L.E., J.M. Wooldrige. (1996). Econometric Methods for Fractional Response Variables with an Application to 401(k) Plan Participation Rates. Journal of Applied Econometrics. 11 619-632.

Rosenkopf, L., A. Nerkar. (2001). Beyond local search: boundary-spanning, exploration, and impact in the optical disk industry. Strategic Management Journal. 22(4) 287- 306.

Rosenkopf, L., P. Almeida. (2003). Overcoming local search through alliances and mobility. Management Science. 49(6) 751-766.

Scotchmer, S. (1991). Standing on the shoulders of giants: Cumulative research and the patent law. The Journal of economic Perspectives. 5(1) 29-41.

Singh, J. (2008). Distributed R\&D, Cross-Regional Knowledge Integration and Quality of Innovative Output. Research Policy. 37(1) 77-96.

Singh, J. and A. Agrawal (2011). Recruiting for Ideas: How Firms Exploit the Prior Inventions of New Hires. Management Science. 57(1) 129-150.

Song, J., P. Almeida P., G. Wu. (2003). Learning by hiring: When is mobility more to facilitate knowledge transfer? Management Science. 49(4) 351-365.

Sørensen, J.B., T.E. Stuart. (2000). Aging, Obsolescence, and Organizational Innovation. Administrative Science Quarterly. 45(1) 81-112.

Trajtenberg, M. (1990). A Penny for Your Quotes: Patent Citations and the Value of Innovations. RAND Journal of Economics. 21(1) 172-187.

Tushman, M. and T. Scanlan. (1981).Boundary Spanning Individuals: Their Role in Information Transfer and Their Antecedents. Academy of Management Journal. 24(2) 289305.

Van Helleputte, J.C., A. Reid. (2004). Tackling the paradox: can attaining global research excellence be compatible with local technology development? R\&D Management. 34(1) 3344.

Ziedonis, A. and R.H. Ziedonis. (2005). Research Consortia as Performers and Brokers of R\&D: Trade-offs for Member Firms. Working paper Ross School. Mimeo. 
Zucker, L.G., M.R. Darby, M.B. Brewer. (1998). Intellectual Capital and the Birth of U.S. Biotechnology Enterprises. American Economic Review. 88(1) 290-306.

Zucker, L.G., M.R. Darby. (2001). Capturing Technological Opportunity via Japan's Star Scientists: Evidence from Japanese Firms' Biotech Patents and Products. The Journal of Technology Transfer. 26(1-2) 37-58.

Zucker, L.G., M.R. Darby, J.S. Armstrong. (2002). Commercializing Knowledge: University Science, Knowledge Capture, and Firm Performance in Biotechnology. Management Science. 48(1) $138-153$. 
Table 1: Patent Types

Partner

\begin{tabular}{|c|c|c|c|}
\hline \multirow{3}{*}{$\begin{array}{l}\text { Boundary-Crossing } \\
\text { Inventor }\end{array}$} & & \multicolumn{2}{|l|}{ Yes } \\
\hline & Yes & $\begin{array}{c}\text { Boundary-Crossing } \\
\text { Partner Patent } \\
\text { (176 patents) } \\
R_{i f}^{B C P}\end{array}$ & $\begin{array}{c}\text { Boundary-Crossing- } \\
\text { NonPartner Patent } \\
\text { (45 patents) } \\
R_{i f}^{B C N P}\end{array}$ \\
\hline & No & $\begin{array}{c}\text { Citing-Partner Patent } \\
\text { (435 patents) } \\
R_{\text {if }}^{C P}\end{array}$ & $\begin{array}{c}\text { Citing-NonPartner } \\
\text { Patent } \\
\text { (433 patents) } \\
R_{\text {if }}^{C N P}\end{array}$ \\
\hline
\end{tabular}


Table 2: Descriptive Statistics

\begin{tabular}{|c|c|c|c|c|c|c|}
\hline & Description Variables & Obs & Mean & Std Dv & Min & Max \\
\hline Count forward citations & $\begin{array}{l}\text { The number of times a patent is cited as } \\
\text { prior art by subsequent patents }\end{array}$ & 1089 & 5.31 & 11.01 & 0 & 131 \\
\hline Count forward citations within 3 years & $\begin{array}{l}\text { The number of times a patent is cited as } \\
\text { prior art by subsequent patents within } \\
\text { three years after publication }\end{array}$ & 1089 & 2.87 & 5.17 & 0 & 61 \\
\hline Forward citations binary & $\begin{array}{l}\text { Dummy indicating whether a patent } \\
\text { received citation(s) }\end{array}$ & 1089 & 0.69 & 0.46 & 0 & 1 \\
\hline Breakthrough Invention binary & $\begin{array}{l}\text { Dummy indicating whether the patent } \\
\text { receives more forward citations than the } \\
\text { mean }+2 * \text { StDev of the number of forward } \\
\text { citations in the same technology class } \\
\text { application year group }\end{array}$ & 1089 & 0.05 & 0.22 & 0 & 1 \\
\hline Count forward self citations & $\begin{array}{l}\text { The number of times a patent is cited by } \\
\text { patents assigned to the same company }\end{array}$ & 1089 & 1.31 & 5.49 & 0 & 116 \\
\hline Count forward self citations within $\mathbf{3}$ years & $\begin{array}{l}\text { The number of times a patent is cited by } \\
\text { patents of the same company within three } \\
\text { years after publication }\end{array}$ & 1089 & 0.81 & 2.23 & 0 & 27 \\
\hline Proportion forward self citations & $\begin{array}{l}\text { The number of self citations divided by } \\
\text { total amount of forward citations }\end{array}$ & 1089 & 0.17 & 0.31 & 0 & 1 \\
\hline Forward self citations binary & $\begin{array}{l}\text { Dummy indicating whether a patent } \\
\text { received self citation(s) }\end{array}$ & 1089 & 0.32 & 0.47 & 0 & 1 \\
\hline Patent scope / Count IPCs & The number of IPC codes & 1089 & 2.58 & 2.07 & 1 & 14 \\
\hline Count non-patent references (NPRS) & $\begin{array}{l}\text { The number of ISI web of knowledge } \\
\text { scientific publications cited }\end{array}$ & 1089 & 7.76 & 15.53 & 0 & 99 \\
\hline Count patent references (PRS) & The number of patents cited by the patent & 1089 & 30.41 & 31.43 & 0 & 147 \\
\hline Count inventors & The number of inventors on the patent & 1089 & 2.94 & 2.10 & 1 & 15 \\
\hline Inventor experience / Count patents ('000) & $\begin{array}{l}\text { The number of patents (in '000) applied } \\
\text { for by the inventors before the application }\end{array}$ & 1089 & 0.07 & 0.15 & 0 & 2 \\
\hline Scale / Count patents last 5 years ('000) & $\begin{array}{l}\text { The number of patents (in '000) the } \\
\text { applicant company applied for in the last } 5 \\
\text { years before the application }\end{array}$ & 1089 & 4.25 & 4.39 & 0 & 20 \\
\hline Scope / Count IPC’s last 5 years ('000) & $\begin{array}{l}\text { The number of unique IPC codes (in '000) } \\
\text { appearing on the company's patents } \\
\text { applied for in the last } 5 \text { years before the } \\
\text { application }\end{array}$ & 1089 & 1.27 & 1.16 & 0 & 5 \\
\hline Age company & $\begin{array}{l}\text { The number of years since the company's } \\
\text { first patent }\end{array}$ & 1089 & 50.92 & 28.19 & 4 & 109 \\
\hline
\end{tabular}

TABLE 3: Descriptive Statistics (Average) by Patent Type

\begin{tabular}{|c|c|c|c|c|c|}
\hline & \multirow{2}{*}{$\begin{array}{c}\text { IMEC } \\
\text { patents }\end{array}$} & \multicolumn{2}{|c|}{ IMEC PARTNER } & \multicolumn{2}{|c|}{ NOT IMEC-PARTNER } \\
\hline & & $\begin{array}{l}\text { BOUNDARY } \\
\text { CROSSING } \\
\text { INVENTOR }\end{array}$ & CITING & $\begin{array}{l}\text { BOUNDARY } \\
\text { CROSSING } \\
\text { INVENTOR }\end{array}$ & CITING \\
\hline Count forward citations & 7.38 & 7.32 & 4.40 & 5.80 & 5.48 \\
\hline Count forward citations within 3 y & 3.25 & 4.42 & 2.38 & 1.69 & 2.86 \\
\hline Forward citations binary & 0.76 & 0.64 & 0.66 & 0.56 & 0.76 \\
\hline Count forward self citations & 0.79 & 2.50 & 1.40 & 0.31 & 0.87 \\
\hline Count forward self citations within $3 \mathrm{y}$ & 0.35 & 1.21 & 0.90 & 0.11 & 0.61 \\
\hline Proportion forward self citations & 0.13 & 0.20 & 0.20 & 0.06 & 0.13 \\
\hline Forward self citations binary & 0.29 & 0.34 & 0.35 & 0.17 & 0.31 \\
\hline Non-Patent Reference binary & 0.81 & 0.60 & 0.60 & 0.47 & 0.65 \\
\hline Number of Observations & 255 & 164 & 433 & 36 & 433 \\
\hline
\end{tabular}


Table 4: Count Forward Patent Citations

\begin{tabular}{|c|c|c|c|c|c|c|c|c|}
\hline & \multicolumn{2}{|c|}{$\begin{array}{c}\text { Poisson } \\
\text { FORWARD CITATIONS }\end{array}$} & \multirow{2}{*}{$\begin{array}{c}\text { Negative } \\
\text { Binomial } \\
\text { FOR CIT } \\
(3) \\
\end{array}$} & \multirow{2}{*}{$\begin{array}{c}\text { ZINB } \\
\text { FOR CIT } \\
(4) \\
\end{array}$} & \multirow{2}{*}{$\begin{array}{c}\text { Poisson } \\
\text { FOR CIT } \\
\text { WITHIN 3Y } \\
(5) \\
\end{array}$} & \multirow{2}{*}{$\begin{array}{c}\text { ZIP } \\
\text { FOR CIT } \\
\text { WITHIN 3Y } \\
(6) \\
\end{array}$} & \multirow{2}{*}{$\begin{array}{c}\text { ZIP } \\
\begin{array}{c}\text { FOR CIT EXCL SELF } \\
\text { WITHIN 3Y }\end{array} \\
\text { (7) } \\
\end{array}$} & \multirow{2}{*}{$\begin{array}{c}\text { ZIP } \\
\text { FOR SELF CIT } \\
\text { WITHIN 3Y } \\
(8)\end{array}$} \\
\hline & (1) & (2) & & & & & & \\
\hline $\begin{array}{l}\text { BOUNDARY CROSSING PARTNER } \\
\text { CITING-PARTNER } \\
\text { BOUNDARY CROSSING NON-PARTNER }\end{array}$ & $\begin{array}{l}0.6612 \\
{[0.504]} \\
-0.0622 \\
{[0.169]} \\
0.2264 \\
{[0.267]} \\
\end{array}$ & $\begin{array}{l}0.5325 * \\
{[0.298]} \\
0.0718 \\
{[0.129]} \\
0.2861 \\
{[0.285]} \\
\end{array}$ & $\begin{array}{l}0.3727 * \\
{[0.226]} \\
0.0604 \\
{[0.128]} \\
0.0897 \\
{[0.319]} \\
\end{array}$ & $\begin{array}{l}0.4080^{*} \\
{[0.222]} \\
0.0538 \\
{[0.128]} \\
0.1435 \\
{[0.262]} \\
\end{array}$ & $\begin{array}{l}0.4754 * \\
{[0.281]} \\
0.0512 \\
{[0.150]} \\
-0.2385 \\
{[0.262]} \\
\end{array}$ & $\begin{array}{c}0.6183 * * * \\
{[0.206]} \\
0.1484 \\
{[0.141]} \\
-0.0726 \\
{[0.292]}\end{array}$ & $\begin{array}{c}0.5673 * * * \\
{[0.192]} \\
-0.0523 \\
{[0.113]} \\
0.1414 \\
{[0.236]}\end{array}$ & $\begin{array}{c}0.6548^{* * *} \\
{[0.230]} \\
0.5335^{* * *} \\
{[0.204]} \\
-1.4783^{* *} \\
{[0.610]}\end{array}$ \\
\hline \multicolumn{9}{|l|}{ PATENT CHARACERISTICS } \\
\hline $\begin{array}{l}\text { Count IPCs } \\
\text { NPRS } \\
\text { PRS } \\
\text { Count inventors } \\
\text { Inventor experience }\end{array}$ & & $\begin{array}{c}0.1296^{* * *} \\
{[0.020]} \\
0.0132^{* * *} \\
{[0.003]} \\
-0.0029 \\
{[0.003]} \\
-0.0198 \\
{[0.023]} \\
0.2285 \\
{[0.385]}\end{array}$ & $\begin{array}{c}0.1117^{* * *} \\
{[0.028]} \\
0.0151^{* * *} \\
{[0.004]} \\
0.0007 \\
{[0.003]} \\
-0.0236 \\
{[0.023]} \\
0.2666 \\
{[0.407]}\end{array}$ & $\begin{array}{c}0.0989 * * * \\
{[0.023]} \\
0.0125 * * * \\
{[0.004]} \\
0.0008 \\
{[0.003]} \\
0.0138 \\
{[0.023]} \\
-0.0573 \\
{[0.319]}\end{array}$ & $\begin{array}{c}0.1310^{* * *} \\
{[0.017]} \\
0.0113^{* * *} \\
{[0.004]} \\
-0.0009 \\
{[0.003]} \\
0.0004 \\
{[0.021]} \\
0.1887 \\
{[0.361]}\end{array}$ & $\begin{array}{c}0.0911^{* * *} \\
{[0.022]} \\
0.0098^{* * *} \\
{[0.003]} \\
-0.0003 \\
{[0.003]} \\
0.0144 \\
{[0.022]} \\
-0.1800 \\
{[0.377]}\end{array}$ & $\begin{array}{c}0.1051^{* * *} \\
{[0.019]} \\
0.0085^{* *} \\
{[0.004]} \\
-0.0025 \\
{[0.003]} \\
-0.0215 \\
{[0.022]} \\
0.1522 \\
{[0.293]}\end{array}$ & $\begin{array}{c}0.0721^{* * *} \\
{[0.019]} \\
0.0020 \\
{[0.003]} \\
0.0041 \\
{[0.003]} \\
0.0903^{* * *} \\
{[0.027]} \\
-0.3963 \\
{[1.384]}\end{array}$ \\
\hline \multicolumn{9}{|l|}{ FIRM CHARACTERISTICS } \\
\hline $\begin{array}{l}\text { Scale } \\
\text { Scope }\end{array}$ & & $\begin{array}{l}0.0160 \\
{[0.019]} \\
-0.0441\end{array}$ & $\begin{array}{l}0.0275^{*} \\
{[0.016]} \\
-0.0695\end{array}$ & $\begin{array}{c}0.0250 \\
{[0.016]} \\
-0.1041^{* *}\end{array}$ & $\begin{array}{c}0.0336^{*} \\
{[0.020]} \\
-0.1414^{*}\end{array}$ & $\begin{array}{c}0.0408^{*} \\
{[0.022]} \\
-0.1577^{* *}\end{array}$ & $\begin{array}{c}0.0416 * * \\
{[0.018]} \\
-0.0702\end{array}$ & $\begin{array}{c}0.0864^{* * *} \\
{[0.031]} \\
-0.5752^{* * *}\end{array}$ \\
\hline Age company & & $\begin{array}{c}{[0.079]} \\
-0.0066^{* *} \\
{[0.003]}\end{array}$ & $\begin{array}{c}{[0.062]} \\
-0.0060^{* *} \\
{[0.002]}\end{array}$ & $\begin{array}{c}{[0.053]} \\
-0.0059^{* *} \\
{[0.003]}\end{array}$ & $\begin{array}{c}{[0.073]} \\
-0.0075^{* * *} \\
{[0.003]}\end{array}$ & $\begin{array}{c}{[0.062]} \\
-0.0069 * * * \\
{[0.003]}\end{array}$ & $\begin{array}{c}{[0.063]} \\
-0.0064^{* *} \\
{[0.003]}\end{array}$ & $\begin{array}{c}{[0.149]} \\
-0.0099 * * \\
{[0.004]}\end{array}$ \\
\hline $\begin{array}{l}\text { Constant } \\
\text { Test of joint significance }\end{array}$ & $\begin{array}{c}1.1066^{* * * *} \\
{[0.294]}\end{array}$ & $\begin{array}{c}1.7725 * * * \\
{[0.336]}\end{array}$ & $\begin{array}{c}1.3417^{* * * *} \\
{[0.303]}\end{array}$ & $\begin{array}{c}1.3746 * * * \\
{[0.316]}\end{array}$ & $\begin{array}{r}-13.8818 \\
{[16.604]}\end{array}$ & $\begin{array}{c}1.3903^{* * *} \\
{[0.199]}\end{array}$ & $\begin{array}{c}1.2536^{* * *} \\
{[0.190]}\end{array}$ & $\begin{array}{l}0.2531 \\
{[0.324]}\end{array}$ \\
\hline $\begin{array}{l}\text { Technology class } \\
\text { Application year }\end{array}$ & $\begin{array}{l}\text { Incl. } \\
\text { Incl. }\end{array}$ & $\begin{array}{l}\text { Incl. } \\
\text { Incl. }\end{array}$ & $\begin{array}{l}\text { Incl. } \\
\text { Incl. }\end{array}$ & $\begin{array}{l}\text { Incl. } \\
\text { Incl. }\end{array}$ & $\begin{array}{l}\text { Incl. } \\
\text { Incl. }\end{array}$ & $\begin{array}{l}\text { Incl. } \\
\text { Incl. }\end{array}$ & $\begin{array}{l}\text { Incl. } \\
\text { Incl. }\end{array}$ & $\begin{array}{l}\text { Incl. } \\
\text { Incl. }\end{array}$ \\
\hline $\begin{array}{l}\text { Log LH/PLH } \\
\text { Observations } \\
\text { (Pseudo) R-squared }\end{array}$ & $\begin{array}{c}-5123.8528 \\
1089 \\
0.308\end{array}$ & $\begin{array}{c}-4605.1141 \\
1089 \\
0.378\end{array}$ & $\begin{array}{c}-2533.7516 \\
1089 \\
0.113\end{array}$ & $\begin{array}{c}-2514.81 \\
1089 \\
0.114\end{array}$ & $\begin{array}{c}-3017.1495 \\
1089 \\
0.231\end{array}$ & $\begin{array}{c}-2671.067 \\
1089 \\
0.196\end{array}$ & $\begin{array}{c}-2233.507 \\
1089 \\
0.175\end{array}$ & $\begin{array}{c}-1114.171 \\
1089 \\
0.184\end{array}$ \\
\hline LINK TEST & & & & & & & & \\
\hline LT1.1 & 2.10 & 2.45 & 1.87 & 2.40 & 2.2 & $4.48^{* *}$ & $9.32^{* * *}$ & 0.29 \\
\hline LT1.2 & 0.72 & 1.01 & 0.08 & 2.39 & 0.83 & 0.06 & 0.36 & $5.88^{* *}$ \\
\hline LT2.1 & 0.68 & 0.46 & 0.58 & 0.71 & $4.35^{* *}$ & $3.96^{* *}$ & 2.22 & $13.5^{* * *}$ \\
\hline LT2.2 & 0.13 & 0.31 & 0.22 & 1.87 & 0.12 & 1.11 & 0.21 & $6.81^{* * *}$ \\
\hline COMPLEMENTARITY TEST & 0.82 & 0.22 & 0.33 & 0.38 & $3.24 *$ & 2.12 & 2.35 & $6.73^{* * *}$ \\
\hline
\end{tabular}

Robust standard errors in brackets, clustered by firm, application year and technology class dummies are used to model the variance term in the negative binomial model *** $\mathrm{p}<0.01, * * \mathrm{p}<0.05, * \mathrm{p}<0.1$

Marginal Effects (3): Crossing-Partner 70\%*; Citing-Partner 7\%; Crossing-NoPartner 33\% 
Table5: Proportion Self-citations

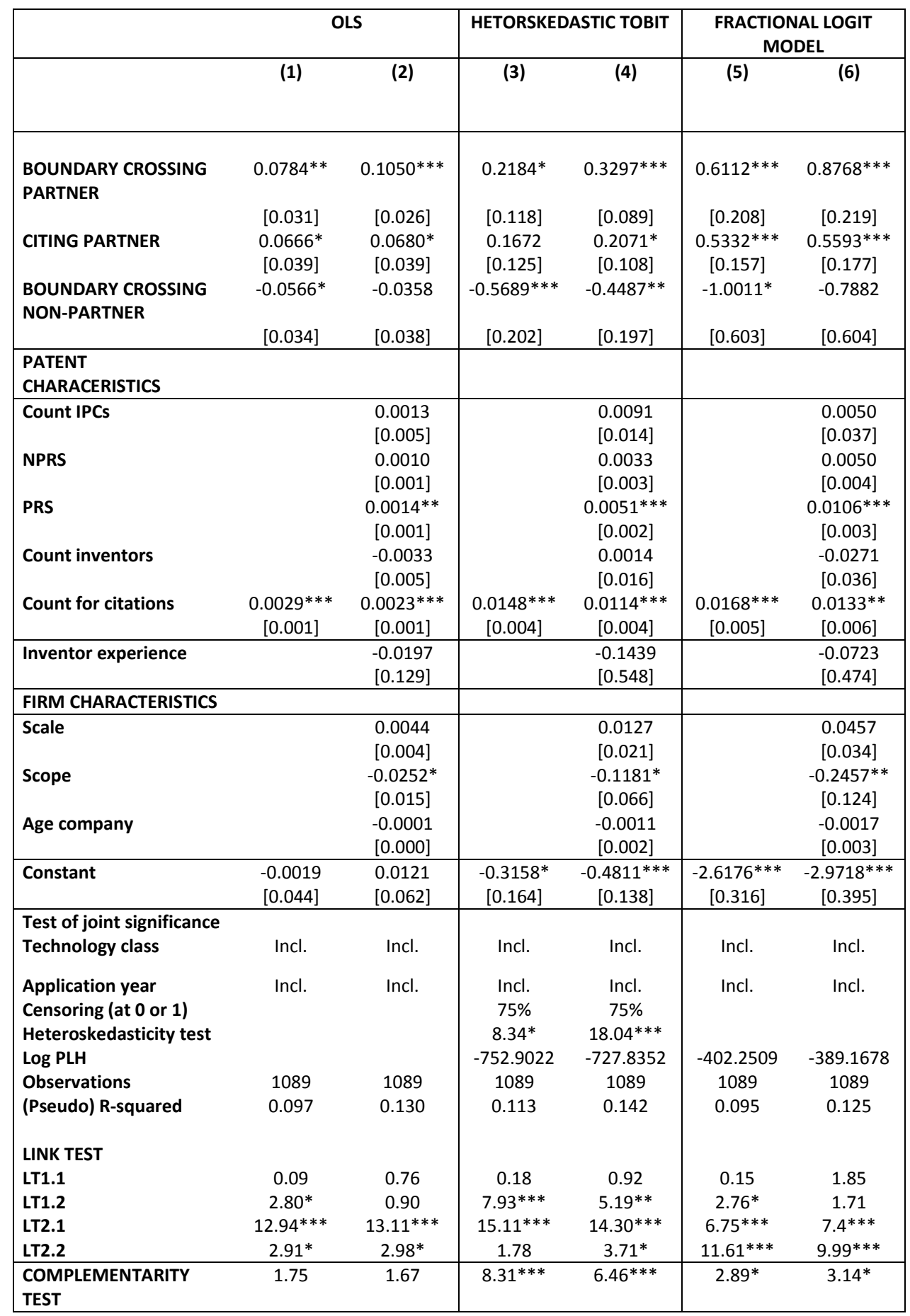

All regressions include application year and technology dummies, Citing-NonPartner patents is control group Robust standard errors in brackets, clustered by firm, heteroskedasticity term includes 4 scale class dummies $* * * p<0.01, * * p<0.05, * p<0.1$

Marginal Effects (6): Crossing-Partner 0.065***, Citing-Partner0.032***, CitingNonPartner $-0.033^{* * *}$ 
Table 6: Robustness Sample Selection

\begin{tabular}{|c|c|c|c|c|c|c|c|c|c|c|}
\hline & \multicolumn{5}{|c|}{ IMEC PARTNER } & \multicolumn{5}{|c|}{ NOT IMEC-PARTNER } \\
\hline & $\begin{array}{l}\text { BOUNDARY } \\
\text { CROSSING } \\
\text { INVENTOR }\end{array}$ & $\begin{array}{c}\text { BOUNDARY } \\
\text { CROSSING } \\
\text { INVENTOR } \\
\text { CITING } \\
\end{array}$ & CITING & $\begin{array}{l}\text { CONTROL } \\
\text { IPC }\end{array}$ & $\begin{array}{l}\text { CONTROL } \\
\text { IPC \& FIRM }\end{array}$ & $\begin{array}{l}\text { BOUNDARY } \\
\text { CROSSING } \\
\text { INVENTOR }\end{array}$ & $\begin{array}{c}\text { BOUNDARY } \\
\text { CROSSING } \\
\text { INVENTOR } \\
\text { CITING } \\
\end{array}$ & CITING & $\begin{array}{c}\text { CONTROL } \\
\text { IPC }\end{array}$ & $\begin{array}{l}\text { CONTROL } \\
\text { IPC \& FIRM }\end{array}$ \\
\hline Count forward citations & 7.32 & 4.92 & 4.40 & 3.61 & 3.93 & 5.80 & 2.44 & 5.48 & 4.15 & 6.80 \\
\hline Count forward citations within $3 \mathrm{y}$ & 4.42 & 4.25 & 2.38 & 2.10 & 2.83 & 1.69 & 1.44 & 2.86 & 1.84 & 1.70 \\
\hline Proportion forward self citations & 0.20 & 0.36 & 0.20 & 0.14 & 0.15 & 0.06 & 0.00 & 0.13 & 0.08 & 0.16 \\
\hline Number of Observations & 164 & 12 & 433 & 176 & 121 & 36 & 9 & 433 & 45 & 20 \\
\hline
\end{tabular}


Table 7: Matched Partner/Non-Partner Patents

\begin{tabular}{|c|c|c|c|c|}
\hline \multicolumn{5}{|c|}{ BOUNDARY CROSSING PARTNER vS CITING NON-PARTNER } \\
\hline & $\begin{array}{l}\text { PARTNER } \\
\text { (TREATED) }\end{array}$ & $\begin{array}{l}\text { NON-PARTNER } \\
\text { (NON-TREATED) }\end{array}$ & $\mathbf{t}$ & $\begin{array}{l}\text { TTEST } \\
P>|t|\end{array}$ \\
\hline Count forward cit 3y & 4.57 & 1.40 & 4.25 & 0.00 \\
\hline Proportion self citations & 0.21 & 0.04 & 5.99 & 0.00 \\
\hline \multicolumn{5}{|c|}{ CITING PARTNER vS CITING NON-PARTNER (LT2.2) } \\
\hline & $\begin{array}{l}\text { PARTNER } \\
\text { (TREATED) }\end{array}$ & $\begin{array}{l}\text { NON-PARTNER } \\
\text { (NON-TREATED) }\end{array}$ & $\mathbf{t}$ & $\begin{array}{l}\text { TTEST } \\
P>|t|\end{array}$ \\
\hline Count forward cit $3 y$ & 2.47 & 2.49 & -0.07 & 0.94 \\
\hline Proportion self citations & 0.20 & 0.07 & 6.74 & 0.00 \\
\hline \multicolumn{5}{|c|}{ BOUNDARY CROSSING PARTNER vS BOUNDARY CROSSING NON-PARTNER (LT2.1) } \\
\hline & $\begin{array}{l}\text { PARTNER } \\
\text { (TREATED) }\end{array}$ & $\begin{array}{l}\text { NON-PARTNER } \\
\text { (NON-TREATED) }\end{array}$ & $\mathbf{t}$ & $\begin{array}{l}\text { TTEST } \\
P>|t|\end{array}$ \\
\hline Count forward cit 3y & 5.39 & 1.69 & 3.91 & 0.00 \\
\hline Proportion self citations & 0.24 & 0.18 & 1.73 & 0.09 \\
\hline
\end{tabular}

Averages do not necessarily match the descriptives of Table 3 as only successfully matched patents within the common support are used in the calculation of the averages. 
APPENDIX: Partner Patent Selection Equation

\begin{tabular}{|c|c|}
\hline VARIABLES & Partner Dummy Patent \\
\hline \multicolumn{2}{|l|}{ PATENT CHARACTERISTICS } \\
\hline \multirow{2}{*}{ Count IPCs } & $-0.0760 * *$ \\
\hline & {$[0.0297]$} \\
\hline \multirow[t]{2}{*}{ NPRS } & $-0.0107^{*}$ \\
\hline & {$[0.0064]$} \\
\hline \multirow[t]{2}{*}{ PRS } & 0.0038 \\
\hline & {$[0.0038]$} \\
\hline \multirow[t]{2}{*}{ Count inventors } & 0.0511 \\
\hline & {$[0.0329]$} \\
\hline \multicolumn{2}{|l|}{ FIRM CORE TECHNOLOGY } \\
\hline \multirow[t]{2}{*}{ Electrical machinery and apparatus, electrical energy } & -0.9625 \\
\hline & [0.9643] \\
\hline \multirow[t]{2}{*}{ Audio-visual technology } & 0.7735 \\
\hline & {$[0.8911]$} \\
\hline \multirow[t]{2}{*}{ Telecommunications } & $-1.5170 * *$ \\
\hline & {$[0.6508]$} \\
\hline \multirow[t]{2}{*}{ Information technology } & 0.5640 \\
\hline & {$[0.6704]$} \\
\hline \multirow[t]{2}{*}{ Semiconductors } & $1.9357^{* * *}$ \\
\hline & {$[0.5286]$} \\
\hline \multirow[t]{2}{*}{ Optics } & $1.6428^{*}$ \\
\hline & {$[0.8448]$} \\
\hline \multirow[t]{2}{*}{ Analysis, measurement, control technology } & 0.7639 \\
\hline & [0.8669] \\
\hline \multirow[t]{2}{*}{ Chemical engineering } & $2.2081^{* *}$ \\
\hline & {$[0.9916]$} \\
\hline \multicolumn{2}{|l|}{ HEADQUARTERS } \\
\hline \multirow[t]{2}{*}{ US } & 0.7623 \\
\hline & {$[0.7775]$} \\
\hline \multirow[t]{2}{*}{ EU } & $3.3017^{* * *}$ \\
\hline & {$[0.9592]$} \\
\hline \multirow[t]{2}{*}{ Japan } & -0.4943 \\
\hline & {$[0.8549]$} \\
\hline \multicolumn{2}{|l|}{ FIRM CHARACTERISTICS } \\
\hline \multirow[t]{2}{*}{ Top 25 firm in sales } & $1.3454^{* *}$ \\
\hline & {$[0.5343]$} \\
\hline \multirow[t]{2}{*}{ Scale } & -0.0989 \\
\hline & {$[0.0915]$} \\
\hline \multirow[t]{2}{*}{ Scope } & 0.4698 \\
\hline & {$[0.3572]$} \\
\hline \multirow[t]{2}{*}{ Age } & 0.0052 \\
\hline & [0.0096] \\
\hline \multirow[t]{2}{*}{ Constant } & $-2.8132^{* * *}$ \\
\hline & [0.8811] \\
\hline Observations & 1089 \\
\hline Pseudo R-squared & 0.446 \\
\hline$\%$ correctly estimated & $82 \%$ \\
\hline
\end{tabular}

